\title{
PI3K/AKT, MAPK and AMPK signalling: protein kinases in glucose homeostasis
}

\section{Simon M. Schultze ${ }^{1,2}$, Brian A. Hemmings ${ }^{2}$, Markus Niessen ${ }^{1}$ and Oliver Tschopp ${ }^{1, *}$}

New therapeutic approaches to counter the increasing prevalence of obesity and type 2 diabetes mellitus are in high demand. Deregulation of the phosphoinositide-3-kinase (PI3K)/v-akt murine thymoma viral oncogene homologue (AKT), mitogen-activated protein kinase (MAPK) and AMP-activated protein kinase (AMPK) pathways, which are essential for glucose homeostasis, often results in obesity and diabetes. Thus, these pathways should be attractive therapeutic targets. However, with the exception of metformin, which is considered to function mainly by activating AMPK, no treatment for the metabolic syndrome based on targeting protein kinases has yet been developed. By contrast, therapies based on the inhibition of the PI3K/AKT and MAPK pathways are already successful in the treatment of diverse cancer types and inflammatory diseases. This contradiction prompted us to review the signal transduction mechanisms of PI3K/AKT, MAPK and AMPK and their roles in glucose homeostasis, and we also discuss current clinical implications.

Metabolic syndrome is generally defined as a cluster of risk factors for cardiovascular disease and type 2 diabetes mellitus (T2DM) including central obesity, arterial hypertension, dyslipidaemia and elevated fasting glucose (Ref. 1). Impaired glucose homeostasis, as observed in patients with metabolic syndrome, frequently progresses to overt T2DM, which in 2010 affected 344 million patients worldwide (Ref. 2). Hyperglycaemia in diabetic patients can lead to life-threatening complications such as coronary heart disease, stroke and nonalcoholic fatty liver disease (Refs 3, 4, 5).

Strict control of the level of circulating glucose within a narrow physiological range supplies sufficient energy for organs and avoids hyperglycaemia. Glucose homeostasis is largely maintained by the insulin-glucagon system, which compensates for physiological fluctuations in blood glucose caused by food intake and physical activity, or by stress conditions such as hypoxia and inflammation.

\footnotetext{
${ }^{1}$ Division of Endocrinology, Diabetes and Clinical Nutrition, University Hospital of Zurich, Zurich, Switzerland

${ }^{2}$ Friedrich Miescher Institute for Biomedical Research, Basel, Switzerland

${ }^{*}$ Corresponding author: Oliver Tschopp, Division of Endocrinology, Diabetes and Clinical Nutrition, University Hospital of Zurich, Raemistrasse 100, 8091 Zurich, Switzerland. E-mail: oliver.tschopp@ usz.ch
} 
Insulin and glucagon are released from $\beta$ - and $\alpha$ cells, respectively, in the endocrine part of the pancreas. Insulin lowers blood glucose by stimulating glucose uptake and storage (glycogen synthesis and lipogenesis) in skeletal muscle and adipose tissue. In the liver, insulin blocks the release and neogenesis of glucose and stimulates glucose storage. In addition, insulin stimulates protein synthesis, regulates mitochondrial biogenesis and blocks autophagy. Glucagon antagonises the action of insulin, mostly in the liver, where it stimulates gluconeogenesis and thereby increases blood glucose level. The secretion of insulin and glucagon is regulated in a reciprocal manner, which avoids glycaemic volatility because of their opposing effects. It was proposed that the glucose-induced secretion of insulin inhibits glucagon secretion from $\alpha$-cells in a paracrine manner (Ref. 6). Furthermore, incretin hormones [e.g. glucagon-like peptide 1 (GLP-1)] secreted postprandially by the gut potentiate glucosemediated insulin secretion and block glucagon secretion (Ref. 7). In addition, physiological conditions such as low intracellular energy level and cellular stress affect whole-body glucose homeostasis by interfering with insulin action.

Signal transduction from a stimulus to the regulation of cellular processes, including those involved in glucose homeostasis, is primarily dependent on protein kinase signalling. On activation, protein kinases determine the output of metabolic processes by transcriptional and post-translational regulation of rate-limiting enzymes, such as glycogen synthase 1 (GYS1) and fatty acid synthase (FASN, FAS). The insulin receptor (INSR, IR) activates various downstream pathways that control energy homeostasis, including phosphoinositide-3-kinase (PI3K)/v-akt murine thymoma viral oncogene homologue [AKT, also known as protein kinase $\mathrm{B}(\mathrm{PKB})]$ and the mitogen-activated protein kinase 3/1 (MAPK3/ 1, ERK1/2). Whereas the PI3K/AKT pathway is considered to be the major effector of metabolic insulin action, insulin-independent kinases also contribute to metabolic control. AMP-activated protein kinase (AMPK) is mostly activated by low intracellular energy levels and inhibits anabolic processes, stimulates energy-producing catabolic processes and lowers blood glucose level. Because correct functioning of the PI3K/ AKT, MAPK and AMPK pathways is essential for proper metabolic control and their dysfunction often leads to impaired glucose homeostasis, these pathways are attractive therapeutic targets (Refs 8, 9, 10). However, PI3K/AKT, MAPK and AMPK are also involved in several other fundamental cellular processes, including cell proliferation and survival, and thus global therapeutic modification of their activities could induce severe side effects.

Today, specific kinase inhibitors are used successfully for immunosuppression and in the treatment of inflammatory disease and diverse cancer types. However, because proper activation of the PI3K/AKT pathway is required for insulin action, kinase inhibitors targeting PI3K/AKT and downstream effectors might impair metabolic control. Even though inappropriate activation of MAPKs, especially of c-Jun N-terminal kinase (MAPK8, JNK), is considered to have a critical role in acquired insulin resistance, no therapies based on MAPKs are available so far. The only drug targeting protein kinase activity that is widely used today in the treatment of insulin resistance and diabetes is metformin, which is thought to operate mainly by activating AMPK. Although our understanding of the role of protein kinases in the regulation of glucose homeostasis has increased significantly during the past decade, only limited translation into therapies against the metabolic syndrome has occurred. The purpose of this present review is to summarise the signal transduction mechanisms involving PI3K/AKT, MAPK and AMPK with respect to their role in glucose homeostasis and to discuss current clinical implications.

\section{The PI3K-AKT signalling pathway is the} major effector of metabolic insulin action Insulin is an indispensable regulator of glucose homeostasis, and T2DM is characterised by postreceptor insulin resistance combined with $\beta$ cell failure. Insulin signalling is initiated by the binding of insulin to the extracellular $\alpha$-subunits of the heterotetrameric IR. This interaction induces conformational changes and facilitates autophosphorylation of tyrosine residues on the intracellular part of membrane-spanning $\beta$-subunits. These phosphotyrosines then attract a family of adaptor molecules, the insulin receptor substrates (IRSs). On interaction with the IR, IRS proteins themselves are tyrosine phosphorylated, which is partially mediated by 
the tyrosine kinase activity of the IR and also by other kinases. Once phosphorylated, IRS proteins attract downstream signalling molecules, thereby linking the activated IR to the various downstream signalling pathways (Ref. 11).

\section{Molecular mechanism of the PI3K/AKT signalling pathway downstream of insulin} The PI3K/AKT pathway is required for insulindependent regulation of systemic and cellular metabolism (Ref. 8). Besides insulin, many other growth factors, cytokines and environmental stresses can activate PI3K/AKT, mainly in the regulation of cell proliferation, motility, differentiation and survival (Ref. 12). Thus, PI3K/AKT action is highly context dependent, which is at least partially mediated by the recruitment of different isoforms of PI3K (including $\mathrm{p} 85 \alpha, \mathrm{p} 110 \alpha, \mathrm{p} 110 \beta$ ) and AKT (AKT1, AKT2, AKT3) downstream of individual stimuli (Refs 13, 14, 15). The AKT isoforms are encoded by individual genes located on different chromosomes, share approximately $80 \%$ identity in their amino acid sequences and form the same protein structure, including an Nterminal pleckstrin homology $(\mathrm{PH})$, a catalytic domain and a C-terminal regulatory domain (Ref. 16). Among the AKT isoforms, AKT2 is considered to be the major isoform required for metabolic insulin action. Although intensively investigated, the exact molecular mechanisms underlying isoform and context specificity are still not fully elucidated. Here we focus on the function of the PI3K/AKT pathway downstream of IR and IRS proteins and its role in glucose homeostasis.

The PI3K/AKT pathway is activated downstream of the IR by binding an SH2 domain within the regulatory subunit of PI3K (p85) to phosphotyrosines in IRS1/2. This leads to recruitment and activation of the catalytic subunit of PI3K (p110). Once activated, PI3K converts phosphatidylinositol-4,5-bisphosphate (PIP2) to phosphatidylinositol-3,4,5-triphosphate (PIP3) at the plasma membrane. AKT binds through its $\mathrm{PH}$ domain to PIP3, which facilitates activation of AKT by upstream kinases. Initially, 3-phosphoinositide-dependent protein kinase-1 (PDPK1, PDK1) induces about $10 \%$ of kinase activity by phosphorylating Thr308 in the catalytic domain of AKT. Subsequently, mammalian target of rapamycin complex 2
(mTORC2), DNA-dependent protein kinase (DNA-PK) and ataxia telangiectasia mutated kinase (ATM) induce full kinase activity of AKT by phosphorylating Ser473 in the regulatory domain. Although DNA-PK can phosphorylate AKT at Ser473 on insulin stimulation in vitro, it is thought to activate AKT in vivo mainly following stress such as DNA damage (Refs 17, $18,19)$. mTORC2 is considered to be the predominant AKT Ser473 kinase downstream of insulin and growth factor stimuli (Ref. 18). On activation, AKT is released from the plasma membrane and translocates to cellular compartments, such as the cytoplasm, mitochondria and nucleus, where it phosphorylates its many substrates. Substrates implicated in the regulation of cellular metabolism include glycogen synthase kinase $3 \beta$ (GSK3 $\beta$ ), forkhead box protein O1 (FOXO1) and AKT substrate 160 (TBC1D4, AS160), which regulate glycogen synthesis, gluconeogenesis and glucose uptake, respectively. AKT also activates mTORC1 by inhibiting tuberous sclerosis complex $1 / 2$ (TSC1/2). Activated mTORC1 upregulates mitochondrial biogenesis, inhibits autophagy and induces protein synthesis by regulation of peroxisome proliferator-activated receptor gamma coactivator $1 \alpha(\mathrm{PGC} 1 \alpha)$, unc-51-like kinase 1 (ULK1), and ribosomal protein S6 kinase (S6K) and eIF4E-binding protein 1 (4E-BP1), respectively. PDK1 also activates isoforms of protein kinase $C(\mathrm{PKC} \lambda / \zeta)$, which are required for Glut4-dependent regulation of glucose uptake. Moreover, AKT and PKC $\lambda / \zeta$ control de novo lipogenesis by regulating lipogenic genes, such as sterol regulatory element-binding transcription factor 1 (SREBF1, SREBP1c) and peroxisome proliferator-activated receptor $\gamma$ $(\operatorname{PPAR} \gamma)$ (Refs 20, 21). The mechanisms by which AKT and $\mathrm{PKC} \lambda / \zeta$ regulate lipogenic genes are not yet completely understood.

The insulin-PI3K/AKT pathway is negatively regulated at different levels. Phosphatases, including protein tyrosine phosphatase nonreceptor type 1 (PTPN1, PTP1B), phosphatase and tensin homologue (PTEN) and protein phosphatase 2A (PP2A), dephosphorylate and thereby inhibit IR, IRS1/2, PIP3 and AKT, respectively. AKT activity can also be inhibited by binding partners, such as thioesterase superfamily member 4 (THEM4, CTMP) and tribbles homologue 3 Drosophila 
(TRIB3) (Refs 22, 23). Whereas the function of most AKT-binding partners in glucose homeostasis remains to be elucidated, TRIB3 was shown to inhibit insulin signalling (Ref. 23). Furthermore, negative-feedback loops are implemented in the PI3K/AKT pathway that downregulate insulin signalling. GSK3 $\beta$, mTORC1 and S6K can phosphorylate IRS on serine residues, which can lead to their ubiquitylation and proteolytic breakdown (reviewed in Refs 12, 24, 25) (Fig. 1).

\section{Genetic alterations in components of the insulin signalling pathway can impair or improve metabolic control}

Many studies have been carried out in mice and humans and have been pivotal in defining the molecular events underlying insulin signalling. Most patients develop insulin resistance and $\mathrm{T} 2 \mathrm{DM}$ as a result of polygenetic predisposition in combination with overnutrition and obesity (acquired insulin resistance). Monogenetic defects causing diabetes account for only $1-5 \%$ of cases and have been found in loci encoding elements of the insulin signalling pathway, transcription factors and rate-limiting enzymes of glucose metabolism (e.g. hepatocyte nuclear factor $4 \alpha$ and glucokinase) and also in mitochondrial genes (Ref. 26). Interestingly, both enhancement of insulin signalling by deletion of negative regulators and specific interference with its action by deleting targets normally activated by insulin can improve metabolic control and protect against diabetes in mice.

\section{From IR to AKT: genetic mutations and their effects on insulin sensitivity in humans and mice}

Patients with loss-of-function mutations in IR are severely insulin resistant and display signs of hyperglycaemia and hyperinsulinaemia, thus indicating that IR is essential for insulin action (Refs 27, 28, 29). Experiments in vitro have confirmed that amino acid substitutions in the tyrosine kinase domain of IR found in patients, such as glycine (G) to valine (V) at position 996 (G996V) and Q1131R, indeed block insulin signalling, as shown by markedly reduced IR tyrosine kinase activity and diminished phosphorylation of IRS1/2 (Refs 28, 30).

Of the postreceptor gene mutations in the insulin signalling cascade, only a few were found to cause severe insulin resistance in humans. Several variants of IRS1 and IRS2 have been identified in patients with insulin resistance. Two IRS1 variants, a common (G972R) and a rare (T608R) polymorphism, were associated with reduced insulin sensitivity in obese men and severe insulin resistance, respectively (Refs 31,32 ). Both polymorphisms are located in regions implicated in PI3K binding and abolished insulin-stimulated PI3K activity in cell culture models (Refs 32, 33). By contrast, variants of IRS2 were not associated with insulin resistance, and their biochemical properties were not characterised (Refs 34, 35). Of the known polymorphisms in $\mathrm{p} 85 \alpha$ and p110 $\beta$ subunits of PI3K, only an R409Q amino acid substitution in $\mathrm{p} 85 \alpha$ was shown to compromise insulin-stimulated PI3K activity (Refs 36, 37). Remarkably, a mutation identified in AKT2 resulting in an $\mathrm{R} 274 \mathrm{H}$ amino acid substitution in the kinase domain was associated with autosomal dominant inherited severe insulin resistance. AKT2 $\mathrm{R} 274 \mathrm{H}$ has greatly reduced kinase activity and acts in a dominant-negative manner in that its overexpression blocks the inhibition of FOXA2 in HepG2 cells and impairs adipocyte differentiation in vitro (Ref. 38).

Findings in transgenic mice complement the above observations. Mice deficient in the IR develop severe hyperglycaemia within hours after birth and die within days as a result of severe ketoacidosis (Refs 39, 40). IRS1-deficient mice have peripheral insulin resistance, but show only slight hyperglycaemia because of compensatory hyperinsulinaemia (Refs 41, 42). A more severe metabolic phenotype was observed in mice deficient in IRS2. These animals are also insulin resistant, but show hyperglycaemia as a result of impaired adaptation of $\beta$-cell mass (Ref. 43). By contrast, specific loss of elements of insulin signalling can also improve metabolic control. It was shown that mice with an adipose-tissue-specific deletion of $I r$ are protected against obesity and obesity-related insulin resistance (Ref. 44). Whereas $\mathrm{p} 85 \alpha \mathrm{R} 409 \mathrm{Q}$ is associated with reduced insulin sensitivity in humans, loss of $\mathrm{p} 85 \alpha$ by mutation of the corresponding gene Pik3r1 (which encodes p85 $\alpha$, p55 $\alpha$ and p50 $\alpha$ ) resulted in improved glucose tolerance and hypoglycaemia in mice (Refs 45,46 ). It was suggested that the loss of $\mathrm{p} 85 \alpha$ is compensated by $550 \alpha$, which generated an increase in PIP3 on insulin stimulation (Ref. 45). However, there 
Figure 1. Simplified view of insulin-stimulated PI3K/AKT signalling and its substrates involved in cellular metabolism. A detailed description is given in the text. Abbreviations: ACACA, ACC, acetyl-CoA carboxylase; AKT, v-akt murine thymoma viral oncogene homologue 1; 4E-BP1, elF4E-binding protein 1; FOXO1, forkhead

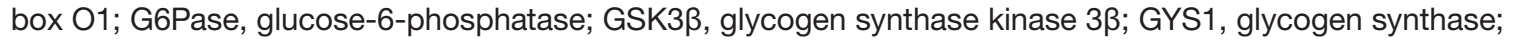
INSR, IR, insulin receptor; IRS1/2, insulin receptor substrates 1/2; ME1, malic enzyme 1; mTORC1, mammalian target of rapamycin complex 1; mTORC2, mTOR complex 2; PDPK1, PDK1, 3-phosphoinositide-dependent protein kinase-1; PGC1a, peroxisome proliferator-activated receptor gamma, coactivator 1 $\alpha$; PI3K, phosphoinositide-3-kinase; PIP2, phosphatidylinositol-4,5-bisphosphate; PIP3, phosphatidylinositol-3,4,5-triphosphate; PKC1, PEPCK, phosphoenolpyruvate carboxykinase 1; $\mathrm{PKC} \lambda / \zeta$, protein kinase $\mathrm{C} \lambda / \zeta$; PPARy, peroxisome proliferator-activated receptor g; PP2A, protein phosphatase 2A; PTPN1, PTP1b, protein tyrosine phosphatase, non-receptor type 1; RPS6, S6, ribosomal protein S6; SCD, stearoyl-CoA desaturase; S6K, ribosomal protein S6 kinase; SLC2A4, GLUT4, solute carrier family 2; SREBF1, SREBP1-C, sterol regulatory element binding transcription factor 1; TBC1D4, AS160, AKT substrate 160; TRIB3, tribbles homologue 3; TSC1/2, tuberous sclerosis complex 1/2; ULK1, unc-51-like kinase 1.

may be further compensatory mechanisms, given that mice lacking all three isoforms of Pik3r1 are also hypoglycaemic (Ref. 46). These studies demonstrate that ablation of proteins can have effects different from loss-of-function mutations and also from inhibitor treatments in which the 
inoperative protein remains present. For detailed descriptions of these mouse models, the reader is referred to another review (Ref. 47).

As described above, loss-of-function mutations in genes of the insulin signalling pathway mostly reduce insulin sensitivity to varying degrees. These findings support the notion that these genes are required for insulin action and are the basis of our understanding of the molecular mechanisms underlying insulin signalling and the development of diabetes. Thus, at first sight, it appears desirable to enhance insulin signalling in order to counteract the development of diabetes. However, the observation that adiposetissue-specific IR deficiency can improve metabolic control and protect against obesity suggests an interesting alternative.

\section{Diverse effects on glucose homeostasis are observed after deletion of individual AKT isoforms and downstream protein kinases in mice}

The mechanisms of insulin signalling at the level of and downstream of, AKT isoforms have been studied extensively in transgenic mouse models. AKT1 and AKT2 are ubiquitously expressed, with high levels in classical insulin target tissues such as the liver, skeletal muscle and adipose tissue (Refs 48, 49). By contrast, the expression of AKT3 appears more restricted and is found mainly in the brain, the testis, adipose tissue and pancreatic islets (Refs 48, 49). As in the case of humans, mice lacking AKT2 are insulin resistant, hyperglycaemic and hyperinsulineamic (Refs 8, 48, 50). Deficiency in AKT3 does not result in metabolic aberrations. However, somewhat conflicting results have been obtained with mice deficient in AKT1. Two studies reported no role for AKT1; however, a third study described higher insulin sensitivity and improved metabolic control (Refs 48, 51, 52). The molecular mechanisms underlying this improved insulin sensitivity in AKT1-deficient mice have not been defined. Although highly similar in structure, loss of individual AKT isoforms results in distinct phenotypes, indicating that AKT isoforms exert nonredundant functions. This can be partially explained by divergent expression patterns, but we are far from understanding the molecular mechanisms underlying specificity (Ref. 15).

The results obtained in mouse models indicate that individual downstream effectors of AKT exert distinct and tissue-specific functions. GSK3 $\beta$ inhibits glycogen synthesis by phosphorylating GYS1 and is negatively regulated by AKT. Accordingly, mice with specific deletion of Gsk3b in skeletal muscle but not in the liver showed improved glucose tolerance owing to enhanced GYS1 activity and glycogen deposition (Ref. 53). Additionally, it was shown that mice with a pancreatic $\beta$-cellspecific deletion of $G s k 3 b$ display increased $\beta$-cell mass and improved glucose tolerance and are protected against genetically and dietinduced diabetes. This increase in $\beta$-cell mass might occur as a result of loss of GSK3 $\beta$ mediated feedback inhibition of insulin signalling, which is known to increase $\beta$-cell proliferation (Refs 54, 55).

mTORC1 and its downstream target S6K are indirectly activated by AKT2, and their roles have also been studied in mice. Activation of mTORC1 in $\beta$-cells by deletion of Tsc1 or Tsc2 increased cell size, proliferation and insulin production. Thus, $\beta$-cell-specific activation of mTORC1 improved glucose-stimulated insulin secretion and glucose tolerance in mice (Refs 56, 57). Conversely, mice with a whole-body S6K deficiency showed reduced $\beta$-cell mass and hypoinsulinaemia (Ref. 58). Ablation of mTORC1 activity in skeletal muscle in mice by deletion of Raptor reduced oxidative capacity by the downregulation of genes involved in mitochondrial biogenesis. Moreover, the glycogen content of the muscle in these mice was increased, most likely because of enhanced inhibition of GSK3 $\beta$ by hyperactivated AKT. As a result, these mice suffered from progressive muscle dystrophy and were glucose intolerant (Ref. 59). Interestingly, mice with an adipocytespecific mTORC1 deficiency as well as those with a whole-body S6K deficiency were protected against diet-induced obesity and insulin resistance. The authors proposed that the protective effects are based on increased energy expenditure and enhanced insulin signalling, which are probably due to loss of negative feedback regulation in adipose tissue (Refs 60, 61). Recently, it was shown that mice with liverspecific activation of mTORC1 by deletion of Tsc1 are glucose intolerant but, are protected against diet-induced hepatic steatosis. The authors also showed that inhibition of mTOR by rapamycin does not reduce hepatic lipid accumulation in mice fed a high-fat diet. Thus, it 
was concluded that mTORC1 is not required and not sufficient to increase hepatic lipids, but rather protects against diet-induced hepatic steatosis by enhancing fat utilisation and gluconeogenesis in the liver (Ref. 62) (Table 1).

These findings show that not only AKT isoforms but also their downstream effectors perform distinct functions in the regulation of glucose homeostasis. Moreover, the impact on metabolic control of modulating the activity of downstream components in the insulin signalling cascade largely depends on the targeted tissue, as demonstrated in the case of mTORC1 and S6K. Thus, the development of techniques for tissue-specific, but not systemic, targeting of downstream components could allow further adaption of current therapies to individual demands, such as improving $\beta$-cell function, reducing hepatic lipid content and restoring insulin response in skeletal muscle.

\section{Improved glucose homeostasis in mice lacking negative regulators of PI3K/AKT}

As mentioned above, phosphatases such as PTP1B and PTEN antagonise insulin signalling. PTP1B downregulates insulin-stimulated PI3K/AKT signalling by dephosphorylating IR and IRS1/2 in a more specific manner than PTEN, which inhibits PI3K/AKT signalling by dephosphorylating PIP3. Because several other growth factors, such as EGF and PDGF, can also increase levels of PIP3 by stimulating PI3K, PTEN appears to be a critical antagonist of all PI3K-dependent AKT stimuli. Notably, both PTP1B deficiency and Pten hemizygosity result in improved glucose tolerance and insulin sensitivity in mice (Refs 63, 64). Similar phenotypes were found in mice with tissuespecific PTP1B deficiency in muscle or liver, and PTEN deficiency in muscle, adipose tissue or liver (Refs 65, 66, 67, 68, 69, 70). Furthermore, it was shown that mice with whole-body and muscle-specific PTP1B deficiency, and mice lacking PTEN in muscle and pancreas, are protected against diet-induced insulin resistance (Refs 63, 65, 67, 71). In contrast to PTP1Bdeficient mice, mice with Pten hemizygosity and mice with PTEN deficiency in hepatocytes develop tumours in various organs or progressive hepatic steatosis with the development of liver cancer, respectively (Refs 69, 70, 72) (Table 2). These phenotypes indicate that PTEN is required to control growth-factor-stimulated PI3K/AKT signalling. Moreover, PTEN was shown to have a phosphatase-independent tumour-suppressive function in the nucleus, which might also have a role in tumour development in mice (Ref. 73).

Recent evidence suggests that the targeting of negative regulators further downstream, such as TRIB3, might enhance insulin signalling without global activation of the PI3K/AKT pathway. Whereas mice with whole-body TRIB3 deficiency showed no alterations in metabolic control under normal conditions, TRIB3 was shown to be upregulated in the liver of diabetic mice and hepatic overexpression of TRIB3 impaired glucose tolerance (Refs 23, 74, 75). Because TRIB3 seems to be dispensable under normal conditions, but seems to contribute to obesity-induced insulin resistance, it might represent an attractive therapeutic target.

As underlined by the complex phenotype of PTEN-deficient mice, the inhibition of negative regulators can lead to global activation of PI3K/AKT with severe side effects such as hepatic steatosis and cancer. Thus, the safe targeting of negative regulators of insulin signalling may be out of reach until the regulation of context-specific stimulation is understood. The targeting of negative regulators further downstream, such as TRIB3, could be more specific and have improved side-effect profiles.

\section{mTOR inhibitors in clinical use and how they affect glucose homeostasis}

Although results from the studies described above show that interfering with $\mathrm{PI} 3 \mathrm{~K} / \mathrm{AKT} / \mathrm{mTOR}$ signalling mostly leads to insulin resistance, its inhibition is an attractive treatment option for various other diseases. Inhibition of PI3K/ AKT/mTOR signalling should be considered especially in cancer therapy, because inappropriate activation of this pathway is frequently observed in many tumour types. Indeed, the mTOR inhibitors temsirolimus and everolimus have been approved for the treatment of metastatic renal cell carcinoma (mRCC) and improve overall or progression-free survival (Refs 76, 77). Current trials explore the efficiency of mTOR inhibitors when used in combination with other therapies, including small-molecule tyrosine kinase inhibitors or VEGF-directed antibodies (Ref. 78). In addition to mRCC, an increasing number of clinical trials study the 
Table 1. Overview of mouse models for AKT isoforms and downstream targets

\begin{tabular}{|c|c|c|c|c|c|}
\hline Gene & Deleted in & $\begin{array}{l}\text { Insulin } \\
\text { sensitivity }\end{array}$ & $\begin{array}{l}\text { Glucose } \\
\text { tolerance }\end{array}$ & Further characteristics & Refs \\
\hline Akt1 & Whole body & + & + & $\begin{array}{l}\text { Reduced body size, increased } \\
\text { neonatal mortality }\end{array}$ & $\begin{array}{l}48 \\
49\end{array}$ \\
\hline \multirow[t]{2}{*}{ Akt2 } & Whole body & - & - & $\begin{array}{l}\text { Diabetes-like phenotype with } \\
\text { compensatory increase in } \\
\text { pancreatic } \beta \text {-cell mass, protected } \\
\text { against genetic- and diet-induced } \\
\text { hepatic steatosis }\end{array}$ & $\begin{array}{l}8,20 \\
48 \\
50 \\
159\end{array}$ \\
\hline & Hepatocytes & NR & NR & $\begin{array}{l}\text { Protected against genetic- and diet- } \\
\text { induced hepatic steatosis }\end{array}$ & 20 \\
\hline Akt3 & Whole body & UC & UC & $\begin{array}{l}\text { Impaired postnatal brain } \\
\text { development, no obvious metabolic } \\
\text { phenotype }\end{array}$ & $\begin{array}{l}48 \\
160\end{array}$ \\
\hline Gsk3a & Whole body & + & + & $\begin{array}{l}\text { Increased hepatic glycogen content, } \\
\text { reduced adipose tissue mass }\end{array}$ & 161 \\
\hline \multirow[t]{5}{*}{ Gsk3b } & $\begin{array}{l}\text { Whole body } \\
(-/-)\end{array}$ & NR & NR & Embryonic lethal & 55 \\
\hline & $\begin{array}{l}\text { Whole body } \\
(+/-)\end{array}$ & NR & NR & $\begin{array}{l}\text { Ameliorates genetically induced } \\
\text { diabetes }\end{array}$ & 55 \\
\hline & $\begin{array}{l}\text { Pancreatic } \\
\beta \text {-cells }\end{array}$ & NR & + & $\begin{array}{l}\text { Increased pancreatic } \beta \text {-cell mass, } \\
\text { protected against diet-induced } \\
\text { diabetes }\end{array}$ & 54 \\
\hline & Hepatocytes & UC & UC & No distinct metabolic phenotype & 53 \\
\hline & $\begin{array}{l}\text { Skeletal } \\
\text { muscle }\end{array}$ & + & + & Increased muscle glycogen content & 53 \\
\hline \multirow[t]{2}{*}{ Tsc1 } & $\begin{array}{l}\text { Pancreatic } \\
\beta \text {-cells }\end{array}$ & - & + & $\begin{array}{l}\text { Increased pancreatic } \beta \text {-cell mass, } \\
\text { improved glycaemic control in young } \\
\text { mice, obesity in old mice }\end{array}$ & 56 \\
\hline & Hepatocytes & - & - & $\begin{array}{l}\text { Protected against diet-induced } \\
\text { hepatic steatosis }\end{array}$ & 62 \\
\hline Tsc2 & $\begin{array}{l}\text { Pancreatic } \\
\beta \text {-cells }\end{array}$ & NR & + & Increased pancreatic $\beta$-cell mass & 57 \\
\hline \multirow[t]{2}{*}{ Raptor } & $\begin{array}{l}\text { Skeletal } \\
\text { muscle }\end{array}$ & NR & - & $\begin{array}{l}\text { Increased muscle glycogen content, } \\
\text { progressive muscle dystrophy }\end{array}$ & 59 \\
\hline & $\begin{array}{l}\text { Adipose } \\
\text { tissue }\end{array}$ & NR & + & $\begin{array}{l}\text { Protected against diet-induced } \\
\text { obesity and hypercholesterolaemia }\end{array}$ & 60 \\
\hline S6k & Whole body & + & - & $\begin{array}{l}\text { Reduced pancreatic } \beta \text {-cell mass, } \\
\text { hypoinsulinaemia, protected against } \\
\text { age- and diet-induced obesity and } \\
\text { insulin resistance }\end{array}$ & $\begin{array}{l}58 \\
61\end{array}$ \\
\hline
\end{tabular}


Table 2. Overview of mouse models for the role of Pten and Ptp1b in glucose homeostasis

\begin{tabular}{|c|c|c|c|c|c|}
\hline Gene & Deleted in & $\begin{array}{l}\text { Insulin } \\
\text { sensitivity }\end{array}$ & $\begin{array}{l}\text { Glucose } \\
\text { tolerance }\end{array}$ & Further characteristics & Refs \\
\hline \multirow[t]{6}{*}{ Pten } & $\begin{array}{l}\text { Whole body } \\
(-/-)\end{array}$ & NR & NR & Embryonic lethal & 64 \\
\hline & $\begin{array}{l}\text { Whole body } \\
(+/-)\end{array}$ & + & + & $\begin{array}{l}\text { Protected against genetically } \\
\text { induced diabetes, spontaneous } \\
\text { tumour development }\end{array}$ & $\begin{array}{l}64 \\
72 \\
162\end{array}$ \\
\hline & $\begin{array}{l}\text { Pancreatic } \\
\beta \text {-cells }\end{array}$ & NR & NR & $\begin{array}{l}\text { Hypoglycaemia, } \\
\text { hypoinsulinaemia, protected } \\
\text { against streptozotocin- and diet- } \\
\text { induced diabetes }\end{array}$ & 71 \\
\hline & $\begin{array}{l}\text { Skeletal } \\
\text { muscle }\end{array}$ & UC & + & $\begin{array}{l}\text { Protected against diet-induced } \\
\text { insulin resistance and diabetes }\end{array}$ & 67 \\
\hline & $\begin{array}{l}\text { Adipose } \\
\text { tissue }\end{array}$ & + & + & $\begin{array}{l}\text { Resistant to streptozotocin- } \\
\text { induced diabetes }\end{array}$ & 68 \\
\hline & Hepatocytes & NR & + & $\begin{array}{l}\text { Age-dependent hepatic steatosis } \\
\text { and its progressive forms }\end{array}$ & 69,70 \\
\hline \multirow[t]{3}{*}{ Ptp1b } & Whole body & + & + & $\begin{array}{l}\text { Protected against diet-induced } \\
\text { diabetes }\end{array}$ & 63 \\
\hline & $\begin{array}{l}\text { Skeletal } \\
\text { muscle }\end{array}$ & + & + & $\begin{array}{l}\text { Protected against diet-induced } \\
\text { insulin resistance }\end{array}$ & 65 \\
\hline & Hepatocytes & + & + & $\begin{array}{l}\text { Reduced hepatic lipid content } \\
\text { after } 5 \text { weeks of a high-fat diet, } \\
\text { protected against diet-induced } \\
\text { insulin resistance }\end{array}$ & 66 \\
\hline
\end{tabular}

effects of mTOR inhibition in other diseases, such as pancreatic neuroendocrine tumours, astrocytomas, lymphangioleiomyomatosis and autosomal dominant polycystic kidney disease (Refs 79, 80, $81,82,83,84)$. Owing to their inhibitory effect on proliferation of lymphocytes, both compounds have also been used for immunosuppression after transplantation.

However, several side effects have been reported, such as myelosuppression, pulmonary toxicity and metabolic disturbances (Refs 85, 86). Treatment of mRCC with mTOR inhibitors was associated with increased blood glucose levels, hypertriglyceridaemia and hypercholesterolaemia (Refs 76, 77). Similarly, the use of mTOR inhibitors after kidney transplantation was linked to elevated cholesterol and triglyceride levels compared with other immunosuppressive regimens and, thus, the subsequent need for lipid-lowering therapy (Ref. 87). Diabetes mellitus is a frequent complication after solid organ transplantation with an increased risk of graft failure and cardiovascular mortality. Whereas immunosuppressive treatments with glucocorticoids and calcineurin inhibitors are known to result in insulin resistance and impaired insulin secretion, respectively, the role of mTOR inhibitors in the development of diabetes after transplantation is more controversial (Refs 88, 89). Some studies indicate an independent association of mTOR inhibitors with diabetes onset after transplantation, but others did not come to the same conclusion (Refs 90, 91, 92).

Although mTOR inhibitors have been implemented successfully in different clinical settings, they may only be used in the treatment 
of specific tumour types, and their efficacy might be limited by cellular escape mechanisms such as rapamycin resistance (Ref. 77). Targeting multiple components of the PI3K/AKT pathway might improve antitumour potency and broaden the spectrum of susceptible tumour types. Indeed, based on structural similarities of PI3K and mTOR, newly developed inhibitors aimed at inhibition of both kinases simultaneously are currently under investigation. In addition to dual PI3K-mTOR inhibitors, selective AKT inhibitors are being tested in xenograft mouse models and early Phase I studies. However, inhibitors targeting multiple components might also have more severe side effects with regard to metabolic control. The use of techniques such as antibody-directed drug delivery could allow cell-type-specific targeting of the PI3K/AKT pathway and thus minimise side effects.

\section{Stress response and MAPK signalling in acquired insulin resistance}

Although at the core of the problem there is still no satisfying answer to the question of how insulin resistance develops, a widely discussed concept involves Ser/Thr kinases, which can phosphorylate numerous sites in IRS1 and IRS2. Phosphorylation of IRS proteins on Ser/Thr residues can uncouple the activated IR from downstream signal transduction modules (reviewed in Ref. 93). This phenomenon potentially depends on three different mechanisms: prevention of docking of IRS to IR, ubiquitylation followed by the proteolytic breakdown of IRS, or prevention of the docking of downstream effectors such as PI3K. Whereas in the former two cases all insulin-induced effects could be abolished, more selective defects might develop in the latter case, dependent on which modules are uncoupled from the activated IR. Multiple negative inputs converge at the level of IRS proteins. Of major importance appears to be the increased secretion of proinflammatory cytokines from adipocytes as observed in obesity. Proinflammatory signalling often involves activation of the inhibitor of $\kappa$ light polypeptide gene enhancer in B-cells, kinase (IKBKB, IKK)-NF- $\mathrm{B}$ axis, which is now regarded as a critical pathway linking obesityassociated chronic inflammation with insulin resistance. For example, tumour necrosis factordependent downregulation of IRS proteins depends on IKK and can be inhibited by aspirin
(Ref. 94). Indeed, that salicylate can increase insulin sensitivity is an old observation (Ref. 95). Whereas IKK-knockout mice are embryonic lethal, mice with IKK hemizygosity show lower fasting blood glucose and insulin levels and improved free fatty acid levels relative to littermate controls when placed on a high-fat diet or rendered leptin deficient (Ref. 96). Furthermore, it has been shown that adipocytederived factors can act through IKK to induce insulin resistance in skeletal muscle (Ref. 97).

In addition to inflammation, the activation of Ser/Thr kinases with concomitant downregulation of the function of IRS proteins has been observed downstream of various conditions known to be associated with the development of insulin resistance and T2DM, such as hypoxia, endoplasmic reticulum (ER) stress and the generation of reactive oxygen species. Kinases activated under these conditions are also called stress kinases, because their activity positively correlates with the occurrence of imbalances in cellular homeostasis. An increase in circulating cytokines, as observed under systemic low-level inflammation during obesity, can also activate IRS Ser/Thr kinases (Ref. 93). Among the kinases targeting IRS are GSK3, S6K, p38 and several isoforms of the PKC family. The PKC family consists of 12 isoforms grouped as atypical PKCs ( $\zeta$ and $\lambda)$, conventional PKCs $(\alpha, \beta$ and $\gamma$ ), novel PKCs $(\delta, \epsilon, \eta$ and $\theta)$, and protein kinase Ns (PKN1, PKN2 and PKN3), from which $\mathrm{PKC} \delta, \mathrm{PKC} \lambda / \zeta$ and PKC $\theta$ are known to target IRS. One widely discussed case is the activation of JNK downstream of ER stress and the unfolded protein response (Refs 98, 99). Obese humans and rodents develop ER stress in hepatocytes and adipocytes, leading to JNKdependent phosphorylation of IRS1 on Ser307 (numbering as in mouse) (Ref. 100) followed by its ubiquitylation and proteolytic breakdown. Indeed, global or conditional loss of JNK in adipose tissue, skeletal muscle or the brain was found to attenuate diet-induced insulin resistance in mice fed a high-fat diet, supporting the notion of a repressive role for JNK in insulin action (Ref. 9). Surprisingly, mice in which the target site for JNK in IRS1 (Ser307) was replaced by an alanine were less insulin sensitive, as were mice lacking JNK1 in hepatocytes (Refs 9, 101). The latter two observations indicate that JNK is required for insulin action in hepatocytes, once more underlining the context dependence of 
insulin signal transduction. The case of JNK exemplifies the dilemma: a significant number of IRS kinases believed to be responsible for the development of insulin resistance are also required for insulin-dependent metabolic control. For example, ERK1/2 are believed to link insulin with cell proliferation, differentiation and the regulation of lipid metabolism, whereas isoforms of PKC may be required for insulin-induced glucose transport (Refs 102, 103, 104, 105, 106, $107,108,109)$. These intricate interconnections certainly complicate the development of intervention strategies based on MAPKs in the treatment of insulin resistance.

\section{AMPK - an energy sensor targeted in the treatment of metabolic syndrome}

When intracellular energy levels are low, cellular metabolism must shift from energy-consuming anabolic processes towards energy-producing catabolic processes. AMPK, a sensor of the availability of intracellular energy, is activated at low energy levels and regulates cellular processes accordingly. This kinase inhibits insulin-stimulated anabolic processes such as de novo lipogenesis and glycogen synthesis. Nevertheless, AMPK activity supports wholebody glucose homeostasis and improves insulin sensitivity by promoting processes such as glucose uptake and energy expenditure. The effects of the widely used antidiabetic drug metformin have been shown to depend largely on activation of AMPK (Ref. 110). Thus, AMPK is currently the only protein kinase targeted in the treatment of metabolic syndrome.

\section{AMPK signalling pathway}

AMPK is a heterotrimeric complex consisting of a catalytic $\alpha$-subunit and two regulatory subunits ( $\beta$ and $\gamma$ ). There are several isoforms of each subunit encoded by individual genes, including PRKAA1 $(\alpha 1)$, PRKAA2 $(\alpha 2)$, PRKAB1 ( $\beta 1)$, PRKAB2 $(\beta 2)$, PRKAG1 $(\gamma 1)$, PRKAG2 $(\gamma 2)$ and PRKAG3 $(\gamma 3)$ (Ref. 111). The different isoforms of AMPK subunits are expressed tissue specifically and exert both overlapping and distinct functions (Refs 112, 113). The AMPK pathway is activated by a variety of physiological stimuli, such as glucose deprivation, hypoxia, oxidative stress and muscle contraction. The common result of these stimuli is a reduction in cellular energy level and an increase in AMP/ATP ratio, which is crucial for AMPK activity. AMPK is also activated by different hormones, including leptin and adiponectin, but the mechanisms by which these hormones activate AMPK are not yet fully elucidated. For full kinase activity, AMPK must be phosphorylated at Thr172 in the catalytic domain of the $\alpha$-subunit by upstream kinases such as serine/threonine kinase 11 (STK11, LKB1) and calcium/calmodulindependent protein kinase kinase $\beta$ (CAMKK $\beta)$. LKB1 is a constitutively active kinase and considered to be the predominant upstream kinase of AMPK, but also phosphorylates 13 other AMPK-related kinases (Ref. 114). Protein phosphatases (PP2A and PP2C) antagonise upstream kinases and inhibit AMPK activity by dephosphorylation of Thr172. Most importantly, AMPK activity and Thr172 phosphorylation are highly dependent on the intracellular AMP/ATP ratio. AMP and ATP bind to the $\gamma$-subunit of AMPK in a competitive manner. When the AMP/ATP ratio is high, binding of AMP to AMPK allosterically activates kinase activity fivefold and induces conformational changes that block the dephosphorylation of Thr172 by PP2A and PP2C, which preserves activation by upstream kinases (reviewed in Refs 111, 115, 116). It has been recently proposed that binding of AMP triggers exposure of a myristoyl group at the AMPK $\beta$-subunit, which promotes membrane association and primes AMPK for activation by upstream kinases (Ref. 117). In addition, it was shown that binding of ADP to AMPK protects against dephosphorylation of Thr172, but does not induce allosteric activation of AMPK (Ref. 118). Activated AMPK phosphorylates substrates such as AS160, GYS1, acetyl-CoA carboxylase $\alpha$ (ACACA, ACC) and malonyl-CoA decarboxylase (MLYCD, MCD), thus stimulating glucose uptake, inhibiting glycogen synthesis, inhibiting de novo lipogenesis and enhancing $\beta$-oxidation, respectively. AMPK also indirectly inhibits mTORC1, thereby blocking protein synthesis, enhancing respiration and probably improving insulin sensitivity by counteracting mTORC1and S6K-induced inhibition of IRS1/2 (reviewed in Ref. 116).

\section{Complex role of AMPK isoforms in metabolic control}

As mentioned above, the antidiabetic effects of metformin largely depend on AMPK activation. Thus, characterising the role of AMPK isoforms 
in mammalian physiology is of great importance and a prerequisite for the achievement of more specific and efficient targeting of AMPK compared with metformin. Genetic mutations in elements of the AMPK pathway in humans and their pathophysiological effects in glucose homeostasis are not yet fully characterised. Several polymorphisms in LKB1 and AMPK $\alpha 2$ and $\gamma 2$ subunits are associated with insulin resistance and T2DM in different subsets of patients (Refs 119, 120, 121). Interestingly, polymorphisms in LKB1, $\alpha 1-, \alpha 2$ - and $\beta 2$ subunits of AMPK as well as in AMPK targets myocyte enhancer factor 2A (MEF2A) and MEF2D were found to be associated with reduced response to metformin treatment (Refs 119, 121). Because metformin is thought to function mainly by activating AMPK, the identified polymorphisms might affect the functions of LKB1, AMPK, MEF2A and MEF2D. However, the physiological and biochemical consequences of the identified polymorphisms remain to be characterised. Apart from that, LKB1 has tumour suppressor functions and its mutation can cause Peutz-Jeghers syndrome, which is characterised by mucocutaneous pigmentation, hamartomatous polyps and increased risk of cancer (Ref. 122). In addition, mutations in PRKAG2 were shown to cause hypertrophic cardiomyopathy with Wolff-Parkinson-White syndrome owing to a glycogen storage disorder (Refs 123, 124, 125).

The complex roles of AMPK isoforms in insulinsensitive tissues have been studied in transgenic mice. Whereas loss of AMPK $\alpha 1$ did not alter metabolic control in mice, global or tissuespecific loss of individual AMPK isoforms mostly led to impaired glucose homeostasis (Ref. 126). PRKA $\alpha 2-$-knockout mice were glucose intolerant and insulin resistant and showed impaired glucose uptake on stimulation with the AMPK activator 5-aminoimidazole-4carboxamide riboside (AICAR) (Refs 10, 126). In addition, deletion of Prkaa 2 specifically in $\beta$-cells resulted in defective glucose-stimulated insulin secretion (Ref. 127). Hepatocyte-specific deletion of Prkaa2 in the liver revealed that AMPK inhibits gluconeogenesis and release of glucose in the liver (Ref. 128). PRKAß2-knockout mice had reduced maximal and endurance exercise capacities and were more susceptible to dietinduced weight gain and glucose intolerance; PRKA $\gamma 3$-knockout mice were shown to have impaired AICAR-stimulated glucose uptake (Refs 129, 130). By contrast, activation of AMPK in the hypothalamus increased food intake, suggesting that inhibition of AMPK in the hypothalamus could protect against obesityinduced insulin resistance (Ref. 131). Indeed, mice lacking AMPK $\beta 1$, which is highly expressed in the liver and brain, were protected against diet-induced obesity, insulin resistance and hepatic steatosis, probably because of reduced food intake (Ref. 132).

These studies show that the effects of AMPK on glucose homeostasis are highly complex as a result of isoform- and tissue-specific functions. Simultaneous modulation of its activity in different tissues can have opposing effects on glucose homeostasis, which could complicate the development of therapeutic approaches directly targeting AMPK. However, isoform- and tissuespecific targeting could also provide a basis for highly specific and effective therapeutic approaches in addition to metformin treatment.

\section{Metformin and AMPK in clinical use}

Metformin has been used in the clinic for several decades for the treatment of insulin-resistant and diabetic patients. The drug improves insulin sensitivity, lowers blood glucose and cholesterol levels without risk of acute hypoglycaemia and weight gain, and reduces the risk of diabetes-related complications such as cardiovascular disease (Ref. 133). The notion that metformin elicits its beneficial effects mainly through the activation of AMPK is further underlined by observations of mice with abolished hepatic AMPK activity due to hepatocyte-specific LKB1 deficiency (Ref. 134). Metformin failed to lower blood glucose in these mice, indicating that activation of AMPK through LKB1 in the liver is required (Ref. 134). Nevertheless, several AMPK-independent effects of metformin have been reported (Ref. 110). It was recently shown that metformin can block gluconeogenesis in isolated mouse hepatocytes independently of LKB1 and AMPK (Ref. 135). The mechanism of AMPK activation by metformin is still controversial. One hypothesis is that metformin activates AMPK indirectly by inhibiting complex I of the respiratory chain, which compromises cellular energy production and increases the AMP/ATP ratio (Refs 136, 137). However, metformin also activates AMPK in an 
adenine-nucleotide-independent manner (Ref. 138). More recently, it was proposed that metformin activates $\mathrm{PKC} \zeta$, which phosphorylates LKB1 at Ser428, resulting in nuclear export of LKB1 and activation of AMPK (Ref. 139). Metformin may mainly activate AMPK in the liver, muscle and vasculature, because cellular uptake of the drug is dependent on transmembrane transporters such as solute carrier family 22 (organic cation transporter), member 1 (SLC22A1, OCT-1). Whereas OCT-1-deficient mice indeed have a diminished response to metformin, the role of OCT-1 polymorphisms in diabetic patients is controversial (Refs 140, 141).

Metformin is used at inconveniently high doses, and its clinical use is restricted in patients with renal or hepatic disease owing to increased risk of lactic acidosis (Ref. 133). Hence, direct activation of AMPK by other means would be an attractive alternative in the treatment of diabetic patients. The AMPK activator A-769662 efficiently lowered blood glucose and triglycerides and transiently reduced body weight gain in mouse models of genetically induced obesity and insulin resistance (Ref. 142). In addition, treatment with AICAR was shown to reduce blood glucose levels in diabetic patients. One side effect associated with the activation of AMPK could be increased food intake because of its role in the hypothalamus. However, treatment with metformin reduces body weight in patients by decreasing appetite and food intake (Refs 143, 144). The underlying mechanisms remain poorly understood (Refs 143, 144). A transient reduction in food intake was reported in obese mice, but not in lean mice treated with A-769662, because this drug may not activate AMPK in the brain (Ref. 142). By contrast, increased food intake was observed in mice treated with AICAR (Refs 131, 145). A-769662 and AICAR were also shown to have AMPKindependent activity, and possible side effects of long-term treatment have not been assessed (Refs 146, 147).

Metformin is now also considered for use in cancer therapy. Epidemiological studies have assessed the association between obesity or T2DM and cancer in large populations (Refs 148, 149). Although intensively investigated, the molecular mechanisms linking cancer with obesity are still not fully elucidated. Chronic hyperinsulinaemia has been suggested to contribute to increased tumour growth, because it may directly activate insulin receptor on (pre-)neoplastic cells or indirectly through promotion of insulin-like growth factor 1 (IGF1) synthesis. Both insulin and IGF1 enhance tumour growth in xenograft models by increasing cell proliferation and inhibiting apoptosis. There is an ongoing debate as to whether the use of insulin analogues in the treatment of obese and diabetic patients could further increase the risk of cancer. Whereas certain insulin analogues do lead to tumour development in rats, their effect in human patients remains controversial (Refs 150, 151, 152). In line with the amelioration of obesity and hyperinsulinemia by metformin, observational data showed that its use was associated with a reduced risk of cancer (Refs 143, 153, 154). Additionally, it might also inhibit tumor progression by AMPK-mediated inhibition of mTORC1, and possibly also by a Rac GTPase-dependent and AMPK-independent mechanism (Ref. 155). Combined cancer therapy with metformin and drugs targeting the PI3K/AKT pathway might result in the synergistic inhibition of mTORC1. This strategy could also overcome impaired glucose homeostasis resulting from PI3K/AKT pathway inhibition.

\section{Concluding remarks}

The insulin signal transduction network and the biochemical properties of its components have been extensively studied. There is increasing knowledge of how PI3K/AKT, MAPK and AMPK signalling controls and how their failure impairs glucose homeostasis. Moreover, studies in transgenic mice have demonstrated that specific modulation of protein kinase signalling can effectively improve glucose homeostasis and protect against obesity, acquired insulin resistance and diabetes. However, very little translation into clinical practice has taken place. Metabolically relevant cellular functions such as glucose transport, lipogenesis, glycogen synthesis and gluconeogenesis are controlled by kinases that do not act exclusively within the insulin signal transduction network. It has emerged that all signal transduction events within a cell are interconnected and that mere description of the network is not sufficient to define mechanisms underlying both context and stimuli specificity. 
Hence, global modulation of kinase activity by, for example deletion of PTEN and the use of mTOR inhibitors might result in severe side effects such as cancer and impaired metabolic control, respectively. The development of safe kinasebased therapies will probably remain elusive until we understand how cells integrate signalling information to implement context in their respective intracellular signal transduction network. In addition, the development of specific inhibitors is complicated by high structural similarities in the catalytic domains of different protein kinases. Reduced specificity resulting in the inhibition of multiple targets could be beneficial in cancer therapy because it might potentiate toxicity on cancer cells. Inhibitors used for the treatment of metabolic syndrome should, by contrast, be highly specific in order to minimise side effects and allow long-term treatment. Targeting kinases in their inactive state, in which they show higher structural diversity than in their active conformation, or disrupting protein complexes of kinases was suggested for the design of inhibitors with increased specificity (Refs 156, 157, 158). Tissuespecific targeting by using transmembrane carriers or metabolic activation, as well as the targeting of specific isoforms or effectors further downstream, might provide a route to increased specificity of drugs and minimal side effects.

\section{Acknowledgements}

We are grateful to P. King and D. Hynx for a critical reading of the manuscript and to the peer reviewers for their constructive and valuable comments. S.M.S. and O.T. were supported by the Swiss SystemsX.ch initiative LiverX of the Competence Center for Systems Physiology and Metabolic Diseases. O.T. was supported by the Amélie Waring foundation. M.N. was supported through participation in COST Action BM0602 and the Takeda Foundation. The FMI is part of the Novartis Research Foundation.

\section{References}

1 Alberti, K.G.M.M. et al. (2009) Harmonizing the metabolic syndrome. Circulation 120, 1640-1645

2 International Diabetes Federation. IDF Diabetes Atlas, 4th edn. Brussels, Belgium: International Diabetes Federation, 2009.

3 Giacco, F. and Brownlee, M. (2010) Oxidative stress and diabetic complications. Circulation Research $107,1058-1070$
4 Roden, M. (2006) Mechanisms of disease: hepatic steatosis in type 2 diabetes - pathogenesis and clinical relevance. Nature Clinical Practice Endocrinology and Metabolism 2, 335-348

5 Chiasson, J.-L. et al. (2003) Diagnosis and treatment of diabetic ketoacidosis and the hyperglycemic hyperosmolar state. Canadian Medical Association Journal 168, 859-866

6 Unger, R.H. and Orci, L. (2010) Paracrinology of islets and the paracrinopathy of diabetes. Proceedings of the National Academy of Sciences of the United States of America 107, 16009-16012

7 Holst, J.J., Vilsboll, T. and Deacon, C.F. (2009) The incretin system and its role in type 2 diabetes mellitus. Molecular and Cellular Endocrinology 297, 127-136

8 Cho, H. et al. (2001) Insulin resistance and a diabetes mellitus-like syndrome in mice lacking the protein kinase Akt2 (PKBbeta). Science 292, 1728-1731

9 Sabio, G. and Davis, R.J. (2010) cJun NH2-terminal kinase 1 (JNK1): roles in metabolic regulation of insulin resistance. Trends in Biochemical Sciences 35, 490-496

10 Viollet, B. et al. (2003) The AMP-activated protein kinase aplha2 catalytic subunit controls wholebody insulin sensitivity. Journal of Clinical Investigation 111, 91-98

11 White, M.F. (2002) IRS proteins and the common path to diabetes. American Journal of Physiology Endocrinology and Metabolism 283, E413-E422

12 Zhuravleva, E., Tschopp, O. and Hemmings, B.A. (2010) Role of PKB/Akt in liver diseases. In Signaling Pathways in Liver Diseases (Dufour J.-F. and Clavien P.-A., eds), Springer, Berlin/ Heidelberg, 243-261

13 Vanhaesebroeck, B. et al. (2010) The emerging mechanisms of isoform-specific PI3K signalling. Nature Reviews. Molecular Cell Biology 11, 329-341

14 Manning, B.D. and Cantley, L.C. (2007) AKT/PKB signaling: navigating downstream. Cell 129, 1261-1274

15 Schultze, S.M. et al. (2011) Promiscuous affairs of $\mathrm{PKB} / \mathrm{AKT}$ isoforms in metabolism. Archives of Physiology and Biochemistry 117, 70-77

16 Hanada, M., Feng, J. and Hemmings, B.A. (2004) Structure, regulation and function of PKB/AKT - a major therapeutic target. Biochimica et Biophysica Acta (BBA) - Proteins and Proteomics 1697, 3-16

17 Feng, J. et al. (2004) Identification of a PKB/Akt hydrophobic motif ser-473 kinase as DNAdependent protein kinase. Journal of Biological Chemistry 279, 41189-41196 
18 Bozulic, L. and Hemmings, B.A. (2009) PIKKing on PKB: regulation of PKB activity by phosphorylation. Current Opinion in Cell Biology 21, 256-261

19 Surucu, B. et al. (2008) In vivo analysis of protein kinase $\mathrm{B}(\mathrm{PKB}) /$ Akt regulation in DNA-PKcs-null mice reveals a role for $\mathrm{PKB} / \mathrm{Akt}$ in DNA damage response and tumorigenesis. Journal of Biological Chemistry 283, 30025-30033

20 Leavens, K.F. et al. (2009) Akt2 is required for hepatic lipid accumulation in models of insulin resistance. Cell Metabolism 10, 405-418

21 Taniguchi, C.M. et al. (2006) Divergent regulation of hepatic glucose and lipid metabolism by phosphoinositide 3-kinase via Akt and PKClambda/zeta. Cell Metabolism 3, 343-353

22 Maira, S.-M. et al. (2001) Carboxyl-terminal modulator protein (CTMP), a negative regulator of $\mathrm{PKB} /$ Akt and v-Akt at the plasma membrane. Science 294, 374-380

23 Du, K. et al. (2003) TRB3: a tribbles homolog that inhibits Akt/PKB activation by insulin in liver. Science 300, 1574-1577

24 Brazil, D.P. and Hemmings, B.A. (2001) Ten years of protein kinase B signalling: a hard Akt to follow. Trends in Biochemical Sciences 26, 657-664

25 Bhaskar, P.T. and Hay, N. (2007) The two TORCs and Akt. Developmental Cell 12, 487-502

26 Permutt, M.A., Wasson, J. and Cox, N. (2005) Genetic epidemiology of diabetes. Journal of Clinical Investigation 115, 1431-1439

27 Kahn, C.R. et al. (1976) The syndromes of insulin resistance and acanthosis nigricans. New England Journal of Medicine 294, 739-745

28 Odawara, M et al. (1989) Human diabetes associated with a mutation in the tyrosine kinase domain of the insulin receptor. Science 245, 66-68

29 Musso, C. et al. (2004) Clinical course of genetic diseases of the insulin receptor (type A and Rabson-Mendenhall syndromes): a 30-year prospective. Medicine 83, 209-222

30 Kishimoto, M. et al. (1994) Substitution of glutamine for arginine 1131. A newly identified mutation in the catalytic loop of the tyrosine kinase domain of the human insulin receptor. Journal of Biological Chemistry 269, 11349-11355

31 Clausen, J.O. et al. (1995) Insulin resistance: interactions between obesity and a common variant of insulin receptor substrate-1. Lancet 346, 397-402

32 Esposito, D.L. et al. (2003) A novel T608R missense mutation in insulin receptor substrate- 1 identified in a subject with type 2 diabetes impairs metabolic insulin signaling. Journal of Clinical Endocrinology Metabolism 88, 1468-1475

33 Almind, K. et al. (1996) A common amino acid polymorphism in insulin receptor substrate-1 causes impaired insulin signaling. Evidence from transfection studies. Journal of Clinical Investigation 97, 2569-2575

34 Bottomley, W. et al. (2009) IRS2 variants and syndromes of severe insulin resistance.

Diabetologia 52, 1208-1211

35 Bernal, D. et al. (1998) Insulin receptor substrate-2 amino acid polymorphisms are not associated with random type 2 diabetes among Caucasians. Diabetes 47, 976-979

36 Kossila, M. et al. (2000) Gene encoding the catalytic subunit p110beta of human phosphatidylinositol 3-kinase: cloning, genomic structure, and screening for variants in patients with type 2 diabetes. Diabetes 49, 1740-1743

37 Baynes, K.C.R. et al. (2000) Natural variants of human p85a; phosphoinositide 3-kinase in severe insulin resistance: a novel variant with impaired insulin-stimulated lipid kinase activity.

Diabetologia 43, 321-331

38 George, S. et al. (2004) A family with severe insulin resistance and diabetes due to a mutation in AKT2. Science 304, 1325-1328

39 Accili, D. et al. (1996) Early neonatal death in mice homozygous for a null allele of the insulin receptor gene. Nature Genetics 12, 106-109

40 Joshi, R.L. et al. (1996) Targeted disruption of the insulin receptor gene in the mouse results in neonatal lethality. EMBO Journal 15, 1542-1547

41 Araki, E. et al. (1994) Alternative pathway of insulin signalling in mice with targeted disruption of the IRS-1 gene. Nature 372, 186-190

42 Tamemoto, H. et al. (1994) Insulin resistance and growth retardation in mice lacking insulin receptor substrate-1. Nature 372, 182-186

43 Withers, D.J. et al. (1998) Disruption of IRS-2 causes type 2 diabetes in mice. Nature 391, 900-904

44 Blüher, M. et al. (2002) Adipose tissue selective insulin receptor knockout protects against obesity and obesity-related glucose intolerance.

Developmental Cell 3, 25-38

45 Terauchi, Y. et al. (1999) Increased insulin sensitivity and hypoglycaemia in mice lacking the p85[alpha] subunit of phosphoinositide 3-kinase. Nature Genetics 21, 230-235

46 Fruman, D.A. et al. (2000) Hypoglycaemia, liver necrosis and perinatal death in mice lacking all 
isoforms of phosphoinositide 3-kinase p85 alpha. Nature Genetics 26, 379-382

47 Lee, A.W.S. and Cox, R.D. (2011) Use of mouse models in studying type 2 diabetes mellitus. Expert Reviews in Molecular Medicine 13, e1

48 Buzzi, F. et al. (2010) Differential effects of protein kinase B/Akt isoforms on glucose homeostasis and Islet mass. Molecular and Cellular Biology 30, 601-612

49 Yang, Z.-Z. et al. (2003) Protein kinase B alpha/ Akt1 regulates placental development and fetal growth. Journal of Biological Chemistry 278, 32124-32131

50 Garofalo, R.S. et al. (2003) Severe diabetes, age-dependent loss of adipose tissue, and mild growth deficiency in mice lacking Akt2/ PKBbeta. Journal of Clinical Investigation 112, 197-208

$51 \mathrm{Cho}$, H. et al. (2001) Akt1/PKBa is required for normal growth but dispensable for maintenance of glucose homeostasis in mice. Journal of Biological Chemistry 276, 38349-38352

52 Chen, W.S. et al. (2001) Growth retardation and increased apoptosis in mice with homozygous disruption of the akt1 gene. Genes and Development 15, 2203-2208

53 Patel, S. et al. (2008) Tissue-specific role of glycogen synthase kinase 3 \{beta\} in glucose homeostasis and insulin action. Molecular and Cellular Biology 28, 6314-6328

54 Liu, Y. et al. (2010) Conditional ablation of Gsk-3 $\beta$ in islet beta cells results in expanded mass and resistance to fat feeding-induced diabetes in mice. Diabetologia 53, 2600-2610

55 Tanabe, K. et al. (2008) Genetic deficiency of glycogen synthase kinase-beta corrects diabetes in mouse models of insulin resistance. PLoS Biology 6, e37

56 Mori, H. et al. (2009) Critical roles for the TSCmTOR pathway in beta-cell function. American Journal of Physiology - Endocrinology and Metabolism 297, E1013-E1022

57 Rachdi, L. et al. (2008) Disruption of Tsc2 in pancreatic beta-cells induces beta-cell mass expansion and improved glucose tolerance in a TORC1-dependent manner. Proceedings of the National Academy of Sciences of the United States of America 105, 9250-9255

58 Pende, M. et al. (2000) Hypoinsulinaemia, glucose intolerance and diminished beta-cell size in S6K1deficient mice. Nature 408, 994-997

59 Bentzinger, C.F. et al. (2008) Skeletal muscle-specific ablation of raptor, but not of rictor, causes metabolic changes and results in muscle dystrophy. Cell Metabolism 8, 411-424
60 Polak, P. et al. (2008) Adipose-specific knockout of raptor results in lean mice with enhanced mitochondrial respiration. Cell Metabolism 8, 399-410

61 Um, S.H. et al. (2004) Absence of S6K1 protects against age- and diet-induced obesity while enhancing insulin sensitivity. Nature 431, 200-205

62 Kenerson, H.L., Yeh, M.M. and Yeung, R.S. (2011) Tuberous sclerosis complex-1 deficiency attenuates diet-induced hepatic lipid accumulation. PLoS ONE 6, e18075

63 Elchebly, M. et al. (1999) Increased insulin sensitivity and obesity resistance in mice lacking the protein tyrosine phosphatase-1B gene. Science 283, 1544-1548

64 Wong, J. et al. (2007) Pten (phosphatase and tensin homologue gene) haploinsufficiency promotes insulin hypersensitivity. Diabetologia 50, 395-403

65 Delibegovic, M. et al. (2007) Improved glucose homeostasis in mice with muscle-specific deletion of protein-tyrosine phosphatase 1B. Molecular and Cellular Biology 27, 7727-7734

66 Delibegovic, M. et al. (2009) Liver-specific deletion of protein-tyrosine phosphatase 1B (PTP1B) improves metabolic syndrome and attenuates dietinduced endoplasmic reticulum stress. Diabetes 58, 590-599

67 Wijesekara, N. et al. (2005) Muscle-specific Pten deletion protects against insulin resistance and diabetes. Molecular and Cellular Biology 25, 1135-1145

68 Kurlawalla-Martinez, C. et al. (2005) Insulin hypersensitivity and resistance to streptozotocininduced diabetes in mice lacking PTEN in adipose tissue. Molecular and Cellular Biology 25, 2498-2510

69 Horie, Y. et al. (2004) Hepatocyte-specific Pten deficiency results in steatohepatitis and hepatocellular carcinomas. Journal of Clinical Investigation 113, 1774-1783

70 Stiles, B. et al. (2004) Liver-specific deletion of negative regulator Pten results in fatty liver and insulin hypersensitivity. Proceedings of the National Academy of Sciences of the United States of America 101, 2082-2087

71 Tong, Z. et al. (2009) Pancreas-specific Pten deficiency causes partial resistance to diabetes and elevated hepatic AKT signaling. Cell Research 19, 710-719

72 Chen, M.-L. et al. (2006) The deficiency of Akt1 is sufficient to suppress tumor development in 
Pten + / - mice. Genes and Development 20, 1569-1574

73 Song, M.S. et al. (2011) Nuclear PTEN regulates the APC-CDH1 tumor-suppressive complex in a phosphatase-independent manner. Cell 144, 187-199

74 Okamoto, H. et al. (2007) Genetic deletion of Trb3, the mammalian drosophila tribbles homolog, displays normal hepatic insulin signaling and glucose homeostasis. Diabetes 56, 1350-1356

75 Koo, S.-H. et al. (2004) PGC-1 promotes insulin resistance in liver through PPAR-alpha-dependent induction of TRB-3. Nature Medicine 10, 530-534

76 Motzer, R.J. et al. (2008) Efficacy of everolimus in advanced renal cell carcinoma: a double-blind, randomised, placebo-controlled phase III trial. Lancet 372, 449-456

77 Hudes, G. et al. (2007) Temsirolimus, interferon alfa, or both for advanced renal-cell carcinoma. New England Journal of Medicine 356, 2271-2281

78 Pal, S. and Figlin, R. (2011) Future directions of mammalian target of rapamycin (mTOR) inhibitor therapy in renal cell carcinoma. Targeted Oncology 6, 5-16

79 Bissler, J.J. et al. (2008) Sirolimus for angiomyolipoma in tuberous sclerosis complex or lymphangioleiomyomatosis. New England Journal of Medicine 358, 140-151

80 Qian, Q. et al. (2008) Sirolimus reduces polycystic liver volume in ADPKD patients. Journal of the American Society of Nephrology 19, 631-638

81 Torres, V.E. et al. (2010) Prospects for mTOR inhibitor use in patients with polycystic kidney disease and hamartomatous diseases. Clinical Journal of the American Society of Nephrology 5, 1312-1329

82 Yao, J.C. et al. (2011) Everolimus for advanced pancreatic neuroendocrine tumors. New England Journal of Medicine 364, 514-523

83 Krueger, D.A. et al. (2010) Everolimus for subependymal giant-cell astrocytomas in tuberous sclerosis. New England Journal of Medicine 363, 1801-1811

84 Witzig, T.E. et al. (2011) A phase II trial of the oral mTOR inhibitor everolimus in relapsed aggressive lymphoma. Leukemia 25, 341-347

85 Cravedi, P., Ruggenenti, P. and Remuzzi, G. (2010) Sirolimus for calcineurin inhibitors in organ transplantation: contra. Kidney International 78, 1068-1074
86 Schaffer, S.A. and Ross, H.J. (2010) Everolimus: efficacy and safety in cardiac transplantation. Expert Opinion on Drug Safety 9, 843-854

87 Kasiske, B.L. et al. (2008) Mammalian target of rapamycin inhibitor dyslipidemia in kidney transplant recipients. American Journal of Transplantation 8, 1384-1392

88 Oterdoom, L.H. et al. (2007) Determinants of insulin resistance in renal transplant recipients. Transplantation 83, 29-35

89 Oetjen, E. et al. (2003) Inhibition of human insulin gene transcription by the immunosuppressive drugs cyclosporin A and tacrolimus in primary, mature Islets of transgenic mice. Molecular Pharmacology 63, 1289-1295

90 Johnston, O. et al. (2008) Sirolimus is associated with new-onset diabetes in kidney transplant recipients. Journal of the American Society of Nephrology 19, 1411-1418

91 Teutonico, A., Schena, P.F. and Di Paolo, S. (2005) Glucose metabolism in renal transplant recipients: effect of calcineurin inhibitor withdrawal and conversion to sirolimus. Journal of the American Society of Nephrology 16, 3128-3135

92 Veroux, M. et al. (2008) New-onset diabetes mellitus after kidney transplantation: the role of immunosuppression. Transplantation Proceedings 40, 1885-1887

93 Boura-Halfon, S. and Zick, Y. (2009) Phosphorylation of IRS proteins, insulin action, and insulin resistance. American Journal of Physiology - Endocrinology and Metabolism 296, E581-E591

94 Gao, Z. et al. (2003) Aspirin inhibits serine phosphorylation of insulin receptor substrate 1 in tumor necrosis factor-treated cells through targeting multiple serine kinases. Journal of Biological Chemistry 278, 24944-24950

95 Arena, F.P., Dugowson, C. and Saudek, C.D. (1978) Salicylate-induced hypoglycemia and ketoacidosis in a nondiabetic adult. Archives of Internal Medicine 138, 1153-1154

96 Yuan, M. et al. (2001) Reversal of obesity- and dietinduced insulin resistance with salicylates or targeted disruption of ikkbeta. Science 293, 1673-1677

97 Dietze, D et al. (2004) Inhibitor kappaB kinase is involved in the paracrine crosstalk between human fat and muscle cells. International Journal of Obesity and Related Metabolic Disorders 28, 985-992 
98 Ozcan, U. et al. (2004) Endoplasmic reticulum stress links obesity, insulin action, and type 2 diabetes. Science 306, 457-461

99 Xu, L., Spinas, G.A. and Niessen, M. (2010) ER stress in adipocytes inhibits insulin signaling, represses lipolysis, and alters the secretion of adipokines without inhibiting glucose transport. Hormone and Metabolic Research 42, 643-651

100 Aguirre, V. et al. (2000) The c-Jun NH2-terminal kinase promotes insulin resistance during association with insulin receptor substrate- 1 and phosphorylation of Ser307. Journal of Biological Chemistry 275, 9047-9054

101 Copps, K.D. et al. (2010) Irs1 serine 307 promotes insulin sensitivity in mice. Cell Metabolism 11, 84-92

102 Avruch, J. (1998) Insulin signal transduction through protein kinase cascades. Molecular and Cellular Biochemistry 182, 31-48

103 Roth, G. et al. (2000) MAP kinases Erk1/2 phosphorylate sterol regulatory element-binding protein (SREBP)-1a at serine 117 in vitro. Journal of Biological Chemistry 275, 33302-33307

104 Kotzka, J. et al. (2004) Insulin-activated Erkmitogen-activated protein kinases phosphorylate sterol regulatory element-binding protein-2 at serine residues 432 and 455 in vivo. Journal of Biological Chemistry 279, 22404-22411

105 Rydén, M. et al. (2004) Targets for TNF-[alpha]induced lipolysis in human adipocytes.

Biochemical and Biophysical Research Communications 318, 168-175

106 Martin, S. and Parton, R.G. (2006) Lipid droplets: a unified view of a dynamic organelle. Nature Reviews. Molecular Cell Biology 7, 373-378

107 Bandyopadhyay, G. et al. (2000) Effects of adenoviral gene transfer of wild-type, constitutively active, and kinase-defective protein kinase C-lambda on insulin-stimulated glucose transport in L6 myotubes. Endocrinology 141, 4120-4127

108 Bandyopadhyay, G. et al. (2002) PKC- $\zeta$ mediates insulin effects on glucose transport in cultured preadipocyte-derived human adipocytes. Journal of Clinical Endocrinology and Metabolism 87, 716-723

109 Sajan, M.P. et al. (2006) Repletion of atypical protein kinase C following RNA interference-mediated depletion restores insulin-stimulated glucose transport. Journal of Biological Chemistry 281, 17466-17473
110 Zhou, G. et al. (2001) Role of AMP-activated protein kinase in mechanism of metformin action. Journal of Clinical Investigation 108, 1167-1174

111 Carling, D. (2004) The AMP-activated protein kinase cascade - a unifying system for energy control. Trends in Biochemical Sciences 29, 18-24

112 Um, J.-H. et al. (2011) AMPK regulates circadian rhythms in a tissue- and isoform-specific manner. PLoS ONE 6, e18450

113 Mahlapuu, M. et al. (2004) Expression profiling of the gamma-subunit isoforms of AMP-activated protein kinase suggests a major role for gamma3 in white skeletal muscle. American Journal of Physiology - Endocrinology and Metabolism 286, E194-E200

114 Lizcano, J.M. et al. (2004) LKB1 is a master kinase that activates 13 kinases of the AMPK subfamily, including MARK/PAR-1. EMBO Journal 23, 833-843

115 Hardie, D.G. (2003) Minireview: the AMPactivated protein kinase cascade: the key sensor of cellular energy status. Endocrinology 144, 5179-5183

116 Witczak, C., Sharoff, C. and Goodyear, L. (2008) AMP-activated protein kinase in skeletal muscle: from structure and localization to its role as a master regulator of cellular metabolism. Cellular and Molecular Life Sciences 65, 3737-3755

117 Oakhill, J.S. et al. (2010) Beta-subunit myristoylation is the gatekeeper for initiating metabolic stress sensing by AMP-activated protein kinase (AMPK). Proceedings of the National Academy of Sciences of the United States of America 107, 19237-19241

118 Xiao, B. et al. (2011) Structure of mammalian AMPK and its regulation by ADP. Nature 472, 230-233

119 Lopez-Bermejo, A. et al. (2010) A single nucleotide polymorphism in STK11 influences insulin sensitivity and metformin efficacy in hyperinsulinemic girls with androgen excess. Diabetes Care 33, 1544-1548

120 Horikoshi, M. et al. (2006) A polymorphism in the AMPKalpha2 subunit gene is associated with insulin resistance and type 2 diabetes in the Japanese population. Diabetes 55, 919-923

121 Jablonski, K.A. et al. (2010) Common variants in 40 genes assessed for diabetes incidence and response to metformin and lifestyle intervention in the diabetes prevention program. Diabetes 59, 2672-2681

122 Mehenni, H. et al. (2007) Molecular and clinical characteristics in 46 families affected with 
Peutz-Jeghers syndrome. Digestive Diseases and Sciences 52, 1924-1933

123 Murphy, R.T. et al. (2005) Adenosine monophosphate-activated protein kinase disease mimicks hypertrophic cardiomyopathy and Wolff-Parkinson-White syndrome: natural history. Journal of the American College of Cardiology 45, 922-930

124 Kim, A.S., Miller, E.J. and Young, L.H. (2009) AMP-activated protein kinase: a core signalling pathway in the heart. Acta Physiologica 196, 37-53

125 Arad, M. et al. (2002) Constitutively active AMP kinase mutations cause glycogen storage disease mimicking hypertrophic cardiomyopathy. Journal of Clinical Investigation 109, 357-362

126 Jorgensen, S.B. et al. (2004) Knockout of the alpha2 but not alpha1 5'-AMP-activated protein kinase isoform abolishes 5-Aminoimidazole-4carboxamide-1-beta-4-ribofuranoside but not contraction-induced glucose uptake in skeletal muscle. Journal of Biological Chemistry 279, 1070-1079

127 Beall, C. et al. (2010) Loss of AMP-activated protein kinase alpha2 subunit in mouse beta-cells impairs glucose-stimulated insulin secretion and inhibits their sensitivity to hypoglycaemia. Biochemical Journal 429, 323-333

128 Andreelli, F. et al. (2006) Liver adenosine monophosphate-activated kinase-alpha2 catalytic subunit is a key target for the control of hepatic glucose production by adiponectin and leptin but not insulin. Endocrinology 147, 2432-2441

129 Steinberg, G.R. et al. (2010) Whole body deletion of AMP-activated protein kinase beta2 reduces muscle AMPK activity and exercise capacity. Journal of Biological Chemistry 285, 37198-37209

130 Barnes, B.R. et al. (2004) The 5'-AMP-activated protein kinase Igamma3 isoform has a key role in carbohydrate and lipid metabolism in glycolytic skeletal muscle. Journal of Biological Chemistry 279, 38441-38447

131 Andersson, U. et al. (2004) AMP-activated protein kinase plays a role in the control of food intake. Journal of Biological Chemistry 279, 12005-12008

132 Dzamko, N. et al. (2010) AMPK beta1 deletion reduces appetite, preventing obesity and hepatic insulin resistance. Journal of Biological Chemistry 285, 115-122

133 UK Prospective Diabetes Study (UKPDS) Group (1998) Effect of intensive blood-glucose control with metformin on complications in overweight patients with type 2 diabetes (UKPDS 34). Lancet 352, 854-865

134 Shaw, R.J. et al. (2005) The kinase LKB1 mediates glucose homeostasis in liver and therapeutic effects of metformin. Science 310, 1642-1646

135 Foretz, M. et al. (2010) Metformin inhibits hepatic gluconeogenesis in mice independently of the LKB1/AMPK pathway via a decrease in hepatic energy state. Journal of Clinical Investigation 120, 2355-2369

136 Owen, M.R., Doran, E. and Halestrap, A.P. (2000) Evidence that metformin exerts its anti-diabetic effects through inhibition of complex 1 of the mitochondrial respiratory chain. Biochemical Journal 348, 607-614

137 Brunmair, B. et al. (2004) Thiazolidinediones, like metformin, inhibit respiratory complex I. Diabetes 53, 1052-1059

138 Hawley, S.A. et al. (2002) The antidiabetic drug metformin activates the AMP-activated protein kinase cascade via an adenine nucleotideindependent mechanism. Diabetes 51, 2420-2425

139 Xie, Z. et al. (2008) Phosphorylation of LKB1 at serine 428 by protein kinase $C$ - $\{$ zeta $\}$ is required for metformin-enhanced activation of the AMPactivated protein kinase in endothelial cells. Circulation 117, 952-962

140 Shu, Y. et al. (2007) Effect of genetic variation in the organic cation transporter 1 (OCT1) on metformin action. Journal of Clinical Investigation 117, 1422-1431

141 Zhou, K. et al. (2009) Reduced-function SLC22A1 polymorphisms encoding organic cation transporter 1 and glycemic response to metformin: a GoDARTS study. Diabetes 58, 1434-1439

142 Cool, B. et al. (2006) Identification and characterization of a small molecule AMPK activator that treats key components of type 2 diabetes and the metabolic syndrome. Cell Metabolism 3, 403-416

143 English, P.J. et al. (2007) Metformin prolongs the postprandial fall in plasma ghrelin concentrations in type 2 diabetes. Diabetes/Metabolism Research and Reviews 23, 299-303

144 Tsilchorozidou, T., Batterham, R.L. and Conway, G.S. (2008) Metformin increases fasting plasma peptide tyrosine tyrosine (PYY) in women with polycystic ovarian syndrome (PCOS). Clinical Endocrinology 69, 936-942

145 Kim, E.-K. et al. (2004) C75, a fatty acid synthase inhibitor, reduces food intake via hypothalamic AMP-activated protein kinase. Journal of Biological Chemistry 279, 19970-19976 
146 Moreno, D. et al. (2008) A769662, a novel activator of AMP-activated protein kinase, inhibits nonproteolytic components of the $26 \mathrm{~S}$ proteasome by an AMPK-independent mechanism. FEBS Letters 582, 2650-2654

147 Santidrian, A.F. et al. (2010) AICAR induces apoptosis independently of AMPK and p53 through up-regulation of the $\mathrm{BH} 3$-only proteins BIM and NOXA in chronic lymphocytic leukemia cells. Blood 116, 3023-3032

148 Giovannucci, E. et al. (2010) Diabetes and cancer: a consensus report. Diabetes Care 33, 1674-1685

149 Calle, E.E. and Kaaks, R. (2004) Overweight, obesity and cancer: epidemiological evidence and proposed mechanisms. Nature Reviews. Cancer 4, 579-591

150 Drejer, K. (1992) The bioactivity of insulin analogues from in vitro receptor binding to in vivo glucose uptake. Diabetes/Metabolism Reviews 8, 259-285

151 Evans, M. et al. (2011) A review of modern insulin analogue pharmacokinetic and pharmacodynamic profiles in type 2 diabetes: improvements and limitations. Diabetes, Obesity and Metabolism 13, 677-684

152 Hansen, B. et al. (2010) Insulin X10 revisited: a super-mitogenic insulin analogue. Diabetologia 54, 2226-2231

153 Jiralerspong, S. et al. (2009) Metformin and pathologic complete responses to neoadjuvant chemotherapy in diabetic patients with breast cancer. Journal of Clinical Oncology 27, 3297-3302
154 Evans, J.M.M. et al. (2005) Metformin and reduced risk of cancer in diabetic patients. BMJ 330, 1304-1305

155 Kalender, A. et al. (2010) Metformin, independent of AMPK, inhibits mTORC1 in a rag GTPase-dependent manner. Cell Metabolism 11, 390-401

156 Sunami, T. et al. (2010) Structural basis of human p70 ribosomal S6 kinase-1 regulation by activation loop phosphorylation. Journal of Biological Chemistry 285, 4587-4594

157 Kaidanovich-Beilin, O. and Eldar-Finkelman, H. (2006) Peptides targeting protein kinases: strategies and implications. Physiology 21, 411-418

158 Pearce, L.R., Komander, D. and Alessi, D.R. (2010) The nuts and bolts of AGC protein kinases. Nature Reviews. Molecular Cell Biology 11, 9-22

159 He, L. et al. (2010) The critical role of AKT2 in hepatic steatosis induced by PTEN loss. American Journal of Pathology 176, 2302-2308

160 Tschopp, O. et al. (2005) Essential role of protein kinase B gamma (PKBgamma/Akt3) in postnatal brain development but not in glucose homeostasis. Development 132, 2943-2954

161 MacAulay, K. et al. (2007) Glycogen synthase kinase 3 alpha-specific regulation of murine hepatic glycogen metabolism. Cell Metabolism 6, 329-337

162 Kushner, J.A. et al. (2005) Phosphatase and tensin homolog regulation of Islet growth and glucose homeostasis. Journal of Biological Chemistry 280, 39388-39393

\section{Further reading, resources and contacts}

Pearce, L.R., Komander, D. and Alessi, D.R. (2010) The nuts and bolts of AGC protein kinases. Nature Reviews. Molecular Cell Biology 11, 9-22

Albert, S.B. et al. (2010) New inhibitors of the mammalian target of rapamycin signaling pathway for cancer. Expert Opinion on Investigational Drugs 19, 919-930.

Gonzalez, E. and McGraw, T.E. (2009) The Akt kinases: isoform specificity in metabolism and cancer. Cell Cycle 8, 2502-2508

Boura-Halfon, S. and Zick, Y. (2009) Phosphorylation of IRS proteins, insulin action, and insulin resistance. American Journal of Physiology - Endocrinology and Metabolism 296, E581-E591.

Diabetesatlas.org is a part of the homepage of The International Diabetes Federation and provides global and regional epidemiology on diabetes:

http://www.idf.org/; http://www.diabetesatlas.org/

Clinicaltrials.gov is a database for clinical trials and provides information on trial purpose and results from over 100000 trials from all over the world:

http://www.clinicaltrials.gov 


\section{Figure}

Figure 1. Simplified view of insulin-stimulated PI3K/AKT signalling and its substrates involved in cellular metabolism.

\section{Tables}

Table 1. Overview of mouse models for AKT isoforms and downstream targets.

Table 2. Overview of mouse models for the role of Pten and Ptp1b in glucose homeostasis.

\section{Citation details for this article}

Simon M. Schultze, Brian A. Hemmings, Markus Niessen and Oliver Tschopp (2012) PI3K/AKT, MAPK and AMPK signalling: protein kinases in glucose homeostasis. Expert Rev. Mol. Med. Vol. 14, e1, January 2012, doi:10.1017/S1462399411002109 